\title{
Antibiofilm, Antioxidant and Quorum Quenching Activities of Propolis Samples from Southwest Anatolia
}

\author{
Özgür Ceylan ${ }^{1, *} \mathbb{D}$, Halime Alıç² \\ ${ }^{1}$ Mugla Sıtkı Koçman University, Ula Ali Kocman Vocational School, Department of Food Processing, Ula- Mugla, Turkey \\ ${ }^{2}$ Mugla Sıtkı Koçman University, Faculty of Sciences, Department of Biology, Kotekli-Mugla, Turkey
}

\section{Article History}

Received 27 November 2020

Accepted 29 December 2020

First Online 30 December 2020

\section{* Corresponding Author \\ Tel.: +902522113284 \\ E-mail: ozgurceylan@mu.edu.tr}

\section{Keywords}

Antimicrobial activity

Minimum Inhibition Concentration Anti-QS

Mugla

\begin{abstract}
In this study, antibiofilm, antioxidant and quorum quenching activities of the ethanol extracts of propolis samples collected from Muğla district were investigated. Antimicrobial activity was determined using the well diffusion and broth tube dilution methods, antibiofilm activity with microplate biofilm method, and antioxidant activity with DPPH radical scavenging, $\beta$-carotene linoleic acid and ferric thiocyanate methods. To determine the antimicrobial activity of the extracts, Listeria monocytogenes ATCC 7944, Streptococcus mutans CNCTC 8/77, Escherichia coli ATCC 25922, Staphylococcus aureus ATCC 25923, Salmonella typhimurium ATCC 14028 and Candida albicans ATCC 10239 strains were used. Minimum inhibitory concentrations (MIC) against microorganisms were determined from 1 to $>100 \mathrm{mg} / \mathrm{ml}$. The lowest MIC value was found as $1 \mathrm{mg} / \mathrm{ml}$ for AP6 propolis extract against Salmonella typhimurium. According to the antibiofilm activity results, highest biofilm were detected at concentrations of MIC as $82.60 \%$ for AP1 against S. mutans, $67.45 \%$ for AP2 against L. monocytogenes, $73.02 \%$ for AP3 against S. mutans, $64.05 \%$ for AP4 against L. monocytogenes, $70.58 \%$ for AP5 against S. typhimurium; $93.43 \%$ for AP6 against S. typhimurium and $72.43 \%$ for AP7 against S. mutans. AP7 extract had the highest antioxidant activity with an $\mathrm{IC}_{50}$ value of $3.94 \mathrm{mg} / \mathrm{ml}$ for DPPH radical scavenging method and with $91.10 \%$ reduction rate for $\beta$-carotene linoleic acid method. AP1 extract had the highest reduction percentage rate of $51.77 \%$ in the ferric thiocyanate method.
\end{abstract}

\section{Introduction}

Propolis is a natural resin, collected mainly by the honey bee, Apis mellifera, which has been shown to have many biological activities including antioxidant and antimicrobial effects, both conferred by phenolic compounds, especially flavonoids (Gonçalves, Santos, \& Srebernich, 2011; Talla et al., 2017; Tamfu et al., 2020). More than 150 components such as polyphenols, phenolic aldehydes, sesquiterpene quinines, coumarins, amino acids, steroids and inorganic components have been identified in propolis samples (Marcucci, 1995; Anjum et al., 2019). Propolis has long been used in oriental folk medicine for curing infections (Cheng \& Wong, 1996; Blicharska \& Seidel, 2019) and in European ethno-pharmacology as an antiseptic and antiinflammatory agent for healing wounds and burns (Ghisalberti, 1979; Rojczyk, Klama-Baryla, Labus,
Wilemska-Kucharzewska, \& Kucharzewska, 2020). Propolis exhibits antimicrobial, antioxidant, antiinflammatory, anaesthetic and other properties (Bankova, de Castro, \& Marcucci, 2000).

The purposes of the study were to determine antibiofilm, antioxidant and quorum quenching activities of propolis samples.

\section{Materials and Methods}

\section{Propolis samples and preparation of alcohol extracts}

Propolis samples were collected from seven different areas; Marmaris (Osmaniye: AP1; Merkez: AP5); Fethiye (Yanıklar: AP2; Uzunyurt: AP3); Datça (AP4); Milas (AP6); and Bodrum (Gümüşlük: AP7) in Muğla located in Southwest Anatolia. Each sample was cut into small pieces after cooling at $-20^{\circ} \mathrm{C}$ and extracted with $96 \%$ 
ethanol $(1: 10 \mathrm{w} / \mathrm{v})$ at $37^{\circ} \mathrm{C}$ for 5 days. The ethyl alcohol extracts were then filtered through a Whatman No. 1 filter paper and evaporated to dryness under vacuum. The samples were kept at $-20^{\circ} \mathrm{C}$ until test experiments (Blonska et al., 2004).

\section{Antibiofilm Activity}

Antibiofilm activities in $\mathrm{MIC}, \mathrm{MIC} / 2, \mathrm{MIC} / 4$ and $\mathrm{MIC} / 8$ concentrations for propolis extracts were determined on polystyrene flat-bottomed microtitre plates as described by Merritt, Kadouri and O'Toole, (2005).

\section{Antioxidant Methods}

\section{Determination of DPPH Radical Scavenging Activity}

Antioxidant activity of the propolis extracts were determined based on its ability to react with the stable 1,1-diphenyl-2-picryl hydrazyl (DPPH) free radical (Burits \& Bucar, 2000) Percentage of inhibition and the concentration of sample required for $50 \%$ scavenging of the DPPH free radical $\left(\mathrm{IC}_{50}\right)$ were determined. BHT and ascorbic acid were used as a positive control.

\section{$\boldsymbol{\beta}$-carotene Linoleic Acid Methods}

$\beta$-Carotene-linoleic acid test system was used to assay lipid-peroxidation inhibitory activity (Dapkevicius, Venskutonis, van Beek, \& Linssen, 1998).

\section{Ferric Thiocyanate (FTC) Method}

A screw-cap vial containing a mixture of $4 \mathrm{mg}$ of sample in $4 \mathrm{~mL}$ of $99.5 \%$ ethanol, $4.1 \mathrm{~mL}$ of $2.51 \%$ linoleic acid in $99.5 \%$ ethanol, $8.0 \mathrm{~mL}$ of $0.02 \mathrm{M}$ phosphate buffer $(\mathrm{pH} 7.0$ ) and $3.9 \mathrm{~mL}$ of water (final concentration $0.02 \%, \mathrm{w} / \mathrm{v}$ ) was placed in an oven at $40^{\circ} \mathrm{C}$ in the dark (Mitsuda, Yuasumoto, \& Iwami, 1996). To $0.1 \mathrm{~mL}$ of this mixture in a test tube, $9.7 \mathrm{~mL}$ of $75 \%(\mathrm{v} / \mathrm{v})$ ethanol, $0.1 \mathrm{~mL} \mathrm{30 \%}$ ammonium thiocyanate and finally, $0.1 \mathrm{~mL}$ of $2 \times 10^{-2} \mathrm{M}$ ferrous chloride in $3.5 \%$ hydrochloric acid was added to the reaction mixture. Three minutes after the addition of ferrous chloride, the absorbance was measured at $500 \mathrm{~nm}$. This step was repeated every $24 \mathrm{~h}$ until the control reached its maximum absorbance value.

\section{Quorum Quenching Activities Methods}

The bacterial strains employed in the study were Chromobacterium violaceum CV026 for anti-quorum sensing, C. violaceum CV12472 for violacein inhibition effects of the propolis extracts. Anti-quorum sensing experiments were carried out according to the methods of Koh and Tam (2011), while the violacein inhibition experiments were performed as described by Choo, Rukayadi, \& Hwang, (2006).

\section{Results}

Prior to investigation of biofilm inhibitory potential of test samples, MIC values of propolis samples were determined on the selected microorganisms and biofilm inhibition assay was performed at MIC and sub-MIC concentrations. The anti-biofilm activity results are given in Table 1 as percentage inhibition values. The antibiofilm activity results showed that the highest biofilm inhibition were observed at MIC concentrations. The antioxidant potential of propolis samples were evaluated using three different methods: DPPH radical scavenging assay, $\beta$-carotene-linoleic acid assay and Ferric thiocynate method and the results presented on Figure 2-4. Prior to quorum quenching activity determination, the MIC values of the propolis extracts were determined against C. violaceum CV 12472 and CV026 and presented in Table 2. The MIC and sub-MIC concentrations were then used for the determination of percentage violacein inhibition of samples (Table 3, Figure 1). The MIC values of the propolis extracts against C. violaceum CV026 biomonitor strain were determined and their QSI evaluated at sub-MIC concentrations (Table 4).

\section{Discussion}

\section{Antibiofilm Activity}

The biofilm inhibitions were determined as $82.60 \%$ for AP1 sample against S. mutans, $67.45 \%$ for AP2 against L. monocytogenes, $93.43 \%$ for AP6 against $S$. typhimurium for MIC concentration. Scazzocchio, D'Auria, Alessandrini, and Pantanella (2006) found a higher rate of S.aureus biofilm inhibition than our study. Koudhi, Zmantar, and Bakhrouf (2010), Dogan et al. (2014) and Capoci et al. (2015) reported higher rates of biofilm inhibition at lower concentrations compared to our results. This can be caused by the difference in the regions of collection of propolis samples.

\section{The Antioxidant Activities}

DPPH radical scavenging, $\beta$-carotene linoleic acid and ferric thiocyanate methods were used for determination of antioxidant activities. The extracts of the propolis sample from Bodrum, Gümüşlük (AP7) showed the highest antioxidant activities with $\mathrm{IC}_{50}$ value of $3.94 \mathrm{mg} / \mathrm{mL}$ for DPPH radical scavenging method and with $91.10 \%$ reduction rate for $\beta$-carotene linoleic acid method. The lowest antioxidant activity was determined as $\mathrm{IC}_{50} 26.33 \mathrm{mg} / \mathrm{mL}$ for DPPH radical scavenging method in AP2. The highest antioxidant activity was shown at AP1 extract with a rate of $51.77 \%$ using ferric thiocyanate method whereas AP4 extract showed the lowest prevention of lipid peroxidation (34.74\%). Nieva Moreno, Isla, Sampieto, and Vattuone (2000) and Lu, Chen, and Chou (2003) reported results consistent with 
Table 1. Antibiofilm activities of propolis extracts at the MIC and sub-MIC concentrations

\begin{tabular}{|c|c|c|c|c|c|c|c|}
\hline Extracts & $\begin{array}{c}\text { Conc. } \\
(\mathrm{mg} / \mathrm{mL})\end{array}$ & C. albicans & S. aureus & S. mutans & L. monocytogenes & E. coli & S. typhimurium \\
\hline \multirow{4}{*}{ AP1 } & MIC & $10.99 \pm 5.84$ & $47.28 \pm 4.19$ & $82.60 \pm 6.92$ & $60.63 \pm 4.75$ & $3.29 \pm 2.36$ & $42.99 \pm 0.40$ \\
\hline & $\mathrm{MIC} / 2$ & - & $29.55 \pm 3.53$ & $73.11 \pm 0.14$ & $48.49 \pm 5.35$ & - & $35.50 \pm 0.60$ \\
\hline & $\mathrm{MIC} / 4$ & - & $11.70 \pm 5.20$ & $71.85 \pm 0.23$ & $32.96 \pm 4.53$ & - & $28.03 \pm 0.26$ \\
\hline & $\mathrm{MIC} / 8$ & - & - & $62.96 \pm 0.15$ & $18.42 \pm 1.76$ & - & $5.59 \pm 0.88$ \\
\hline \multirow{4}{*}{ AP2 } & MIC & - & $35.37 \pm 2.85$ & $46.21 \pm 7.84$ & $67.45 \pm 1.77$ & $8.88 \pm 0.55$ & $60.23 \pm 4.57$ \\
\hline & $\mathrm{MIC} / 2$ & - & $10.39 \pm 0.63$ & $36.45 \pm 2.73$ & $53.89 \pm 1.00$ & - & $40.64 \pm 1.02$ \\
\hline & $\mathrm{MIC} / 4$ & - & $1.76 \pm 3.38$ & $21.95 \pm 1.02$ & $45.62 \pm 0.52$ & - & $26.63 \pm 0.21$ \\
\hline & $\mathrm{MIC} / 8$ & - & - & - & $27.62 \pm 5.07$ & - & $7.48 \pm 1.00$ \\
\hline \multirow{4}{*}{ AP3 } & MIC & $14.59 \pm 1.19$ & $65.24 \pm 0.20$ & $73.02 \pm 1.39$ & $18.96 \pm 3.58$ & $10.28 \pm 0.09$ & $38.78 \pm 0.10$ \\
\hline & $\mathrm{MIC} / 2$ & $5.16 \pm 4.11$ & $53.62 \pm 0.78$ & $56.77 \pm 1.36$ & - & - & $28.01 \pm 2.54$ \\
\hline & $\mathrm{MIC} / 4$ & - & $39.53 \pm 4.57$ & $31.04 \pm 2.67$ & - & - & $10.73 \pm 1.30$ \\
\hline & $\mathrm{MIC} / 8$ & - & $27.19 \pm 4.42$ & $14.03 \pm 4.57$ & - & - & - \\
\hline \multirow{4}{*}{ AP4 } & MIC & $10.92 \pm 1.44$ & $32.76 \pm 1.05$ & $61.98 \pm 1.52$ & $64.05 \pm 2.29$ & $9.34 \pm 0.08$ & $58.41 \pm 0.07$ \\
\hline & $\mathrm{MIC} / 2$ & $7.79 \pm 1.48$ & $23.88 \pm 1.11$ & $50.58 \pm 0.58$ & $51.45 \pm 0.47$ & - & $41.07 \pm 5.22$ \\
\hline & $\mathrm{MIC} / 4$ & $6.74 \pm 2.53$ & $7.37 \pm 0.75$ & $32.21 \pm 3.83$ & $38.77 \pm 6.41$ & - & $22.88 \pm 1.18$ \\
\hline & $\mathrm{MIC} / 8$ & $1.56 \pm 0.53$ & - & $8.51 \pm 3.11$ & $24.21 \pm 5.59$ & - & $3.72 \pm 1.83$ \\
\hline \multirow{4}{*}{ AP5 } & MIC & $51.53 \pm 3.10$ & $46.58 \pm 2.68$ & $61.40 \pm 2.10$ & $70.41 \pm 3.11$ & $13.56 \pm 1.52$ & $70.58 \pm 2.06$ \\
\hline & $\mathrm{MIC} / 2$ & $26.58 \pm 1.83$ & $31.29 \pm 0.41$ & $40.90 \pm 3.69$ & $62.67 \pm 5.94$ & - & $44.88 \pm 3.22$ \\
\hline & $\mathrm{MIC} / 4$ & - & $15.40 \pm 0.77$ & $35.02 \pm 2.99$ & $50.92 \pm 4.84$ & - & $19.57 \pm 5.42$ \\
\hline & $\mathrm{MIC} / 8$ & - & - & $10.63 \pm 0.17$ & $34.94 \pm 0.63$ & - & $1.88 \pm 1.88$ \\
\hline \multirow{4}{*}{ AP6 } & MIC & $28.14 \pm 3.37$ & $26.41 \pm 4.46$ & $86.47 \pm 5.38$ & $68.43 \pm 0.79$ & $14.50 \pm 2.47$ & $93.43 \pm 1.93$ \\
\hline & $\mathrm{MIC} / 2$ & $13.58 \pm 4.30$ & $18.50 \pm 0.61$ & $61.98 \pm 1.52$ & $36.37 \pm 3.04$ & - & $82.73 \pm 2.17$ \\
\hline & $\mathrm{MIC} / 4$ & $7.29 \pm 0.07$ & - & $32.40 \pm 1.31$ & $12.66 \pm 4.00$ & - & $75.22 \pm 0.69$ \\
\hline & $\mathrm{MIC} / 8$ & - & - & $18.85 \pm 1.41$ & - & - & $49.07 \pm 0.92$ \\
\hline \multirow{4}{*}{ AP7 } & MIC & $59.88 \pm 0.93$ & $54.15 \pm 1.94$ & $72.43 \pm 0.81$ & $61.12 \pm 4.26$ & $12.10 \pm 4.55$ & $64.45 \pm 3.13$ \\
\hline & $\mathrm{MIC} / 2$ & $41.67 \pm 0.43$ & $44.01 \pm 0.10$ & $56.00 \pm 3.29$ & $46.10 \pm 1.00$ & - & $53.24 \pm 3.24$ \\
\hline & $\mathrm{MIC} / 4$ & $24.97 \pm 2.86$ & $26.28 \pm 0.54$ & $39.26 \pm 1.42$ & $32.98 \pm 2.59$ & - & $35.97 \pm 1.06$ \\
\hline & $\mathrm{MIC} / 8$ & - & $12.30 \pm 0.92$ & $21.57 \pm 4.00$ & $15.56 \pm 3.06$ & - & $26.15 \pm 1.62$ \\
\hline
\end{tabular}

-: No activity

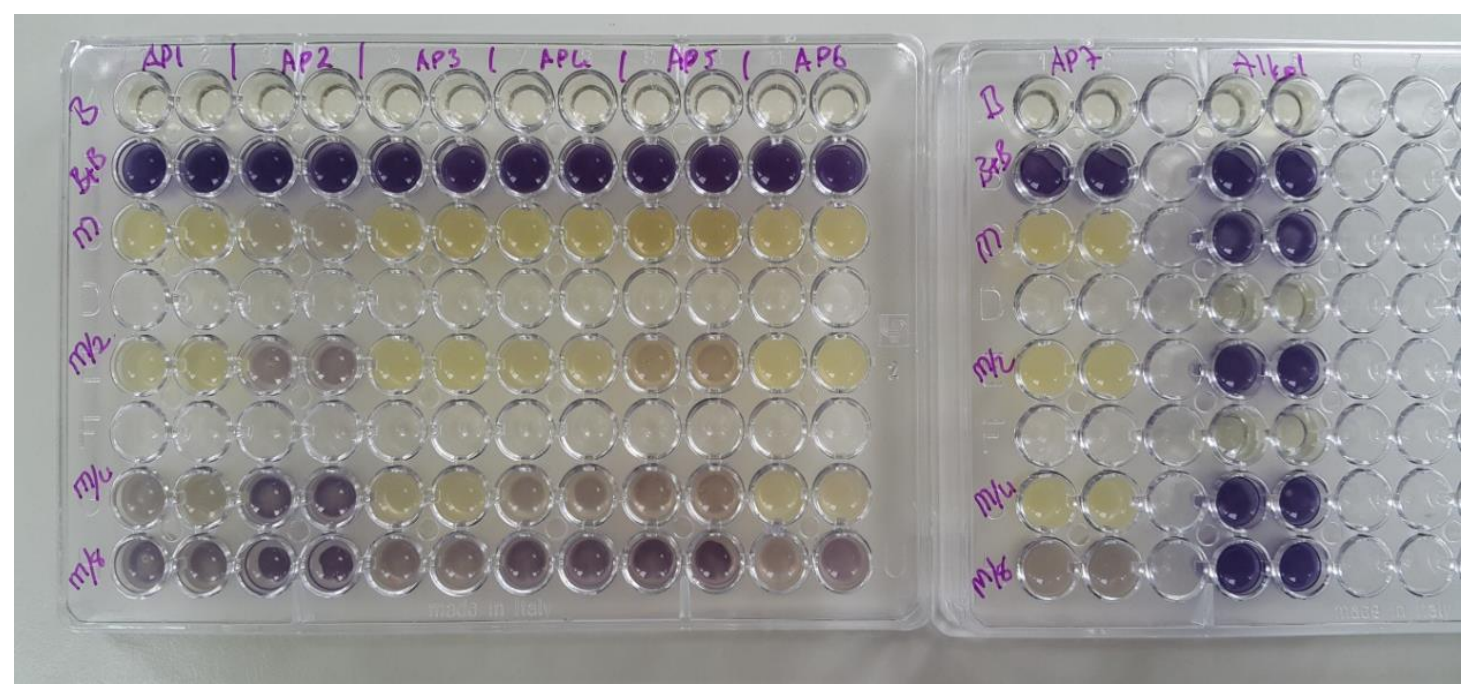

Figure 1. Violacein production inhibition results of propolis extracts against CV 12472 


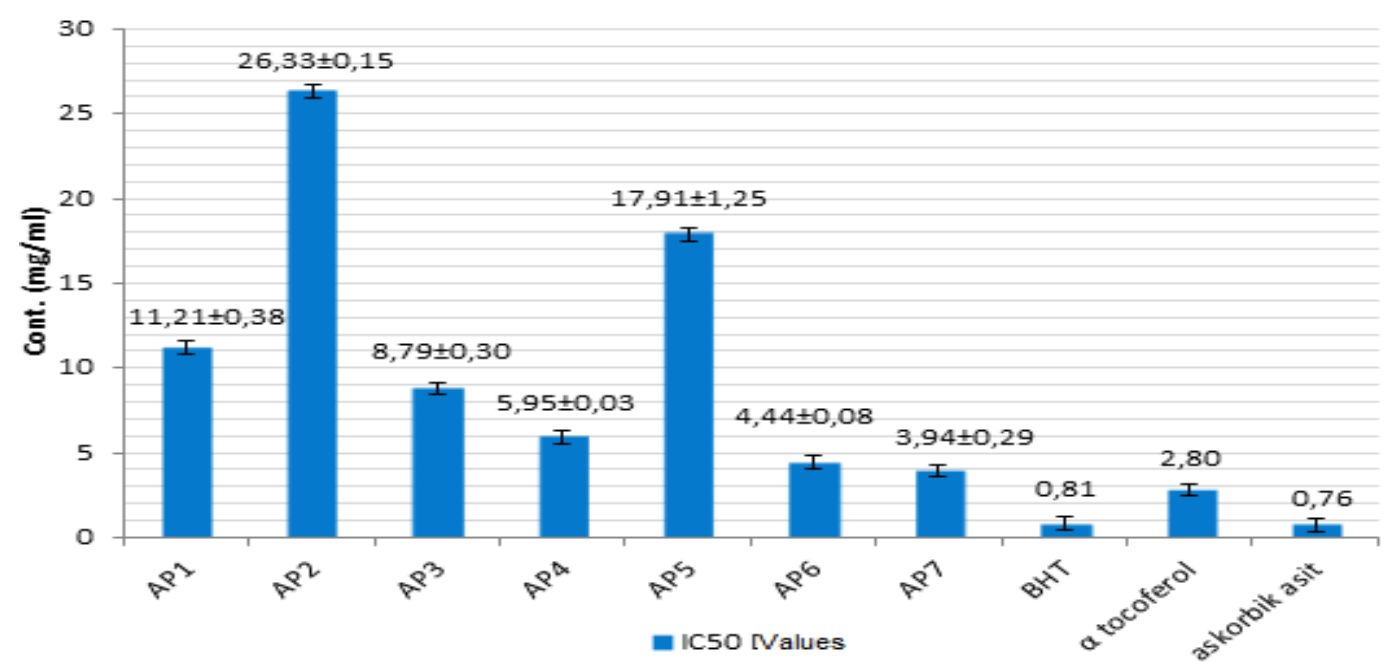

Figure 2. Results of DPPH free radical scavenging activities of propolis extracts,

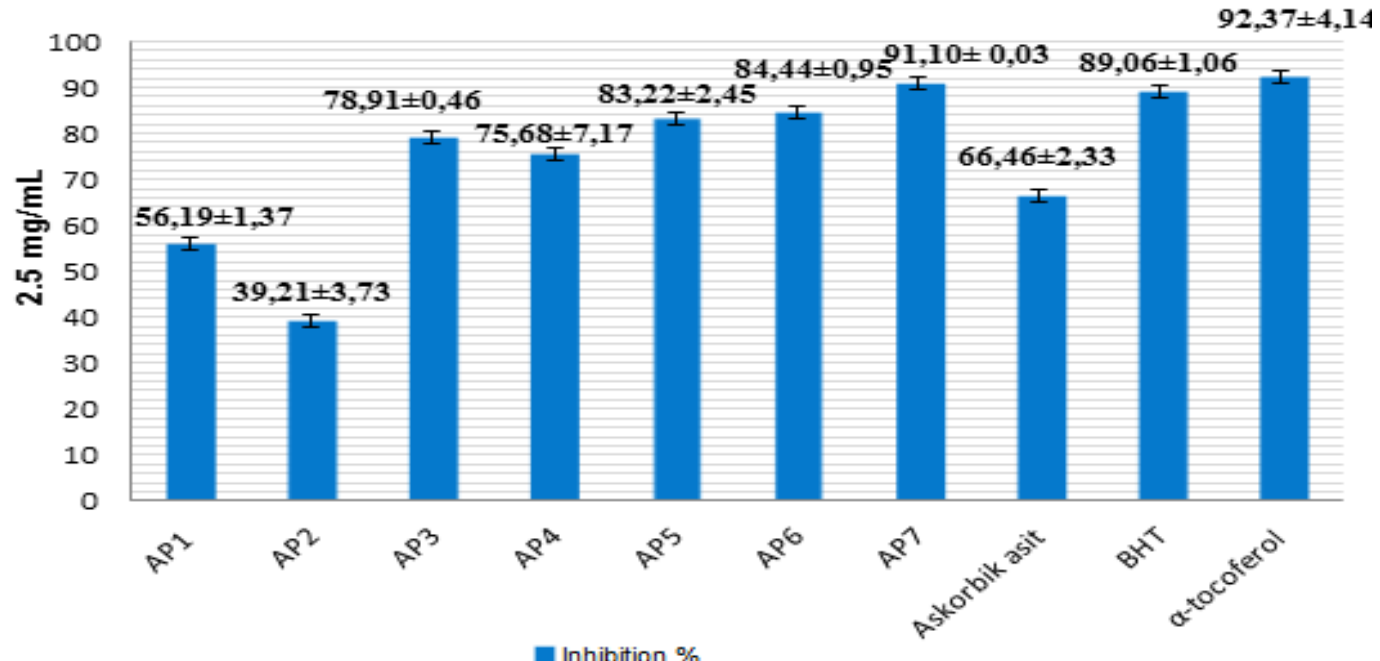

Figure 3. $\beta$-carotene-linoleic acid assay results of Propolis extracts

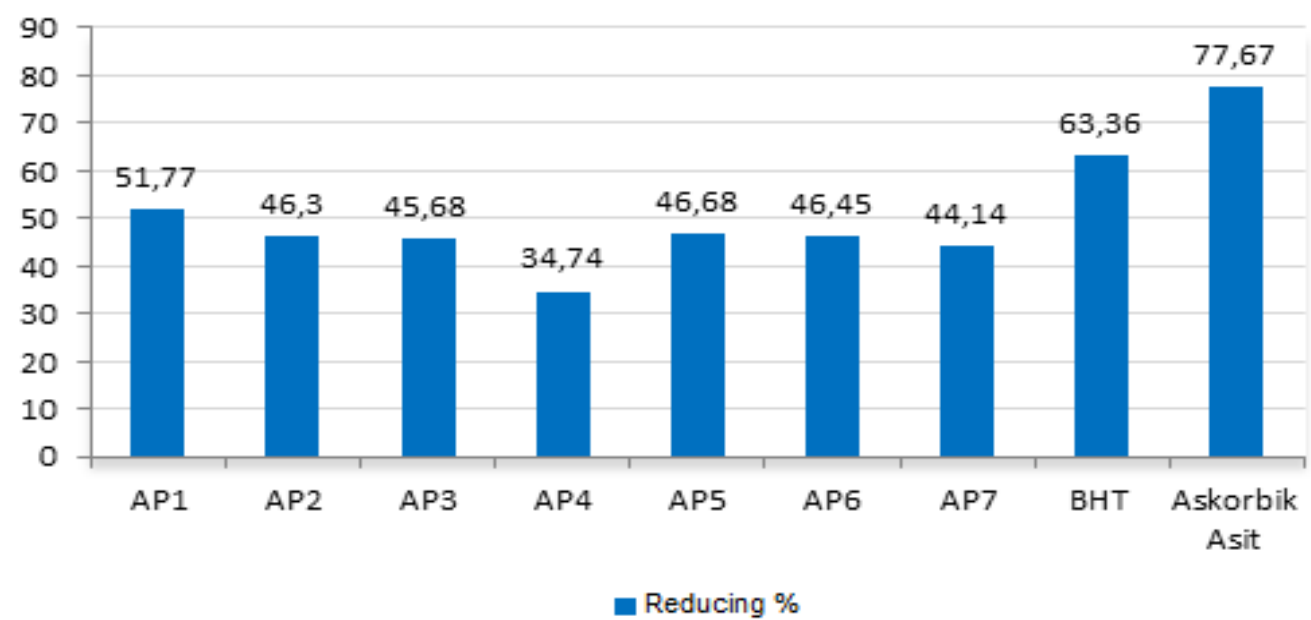

Figure 4. FTC result graph of propolis extracts (\% inhibition) 
Table 2. MIC concentrations against C. violaceum CV 12472 and C. violaceum CV 026 strains

\begin{tabular}{lcc}
\hline Samples & CV12472 & CV026 \\
\cline { 2 - 3 } & & MIC Conc. $(\mathrm{mg} / \mathrm{mL})$ \\
AP1 & 6.25 & 6.25 \\
AP2 & 6.25 & 6.25 \\
AP3 & 6.25 & 6.25 \\
AP4 & 3.12 & 6.25 \\
AP5 & 12.5 & 12.5 \\
AP6 & 3.12 & 3.12 \\
AP7 & 3.12 & 3.12 \\
\hline
\end{tabular}

Table 3. Violacein inhibition rates of propolis extracts against C. violaceum CV 12472

\begin{tabular}{lccccccc}
\hline & \multicolumn{7}{c}{ Violacein inhibition (\%) } \\
\cline { 2 - 8 } Conc. & AP1 & AP2 & AP3 & AP4 & AP5 & AP6 & AP7 \\
\hline MIC & 100 & $64.8 \pm 0.5$ & 100 & 100 & 100 & 100 & 100 \\
MIC/2 & 100 & $39.8 \pm 0.2$ & 100 & 100 & $51.8 \pm 1.8$ & 100 & 100 \\
MIC/4 & $47.1 \pm 1.2$ & $29.2 \pm 0.5$ & 100 & $50.4 \pm 3.7$ & $48.9 \pm 0.6$ & 100 & 100 \\
MIC/8 & $41.2 \pm 0.8$ & $23.1 \pm 0.3$ & $49.7 \pm 1.0$ & $34.6 \pm 1.1$ & $37.3 \pm 0.5$ & $45.6 \pm 2.8$ & $51.0 \pm 0.4$ \\
\hline
\end{tabular}

Table 4. Antiquorum sensing activity results of propolis extracts

\begin{tabular}{|c|c|c|c|}
\hline \multirow[t]{2}{*}{ Propolis extracts } & \multirow[t]{2}{*}{ Concentrations (mg/mL) } & \multicolumn{2}{|c|}{ C. violaceum CV026 } \\
\hline & & Antimicrobial zone (mm) & QS inhibition zone ( $\mathrm{mm})$ \\
\hline \multirow[t]{3}{*}{ AP1 } & MIC & - & - \\
\hline & $\mathrm{MIC} / 2$ & - & - \\
\hline & $\mathrm{MIC} / 4$ & - & - \\
\hline \multirow[t]{3}{*}{ AP2 } & MIC & - & - \\
\hline & $\mathrm{MIC} / 2$ & - & - \\
\hline & $\mathrm{MIC} / 4$ & - & - \\
\hline \multirow[t]{3}{*}{ AP3 } & MIC & - & - \\
\hline & $\mathrm{MIC} / 2$ & - & - \\
\hline & $\mathrm{MIC} / 4$ & - & - \\
\hline \multirow[t]{3}{*}{ AP4 } & MIC & - & 9 \\
\hline & $\mathrm{MIC} / 2$ & - & - \\
\hline & $\mathrm{MIC} / 4$ & - & - \\
\hline \multirow[t]{3}{*}{ AP5 } & MIC & - & - \\
\hline & $\mathrm{MIC} / 2$ & - & - \\
\hline & $\mathrm{MIC} / 4$ & - & - \\
\hline \multirow[t]{3}{*}{ AP6 } & MIC & 8 & 10 \\
\hline & $\mathrm{MIC} / 2$ & 7 & - \\
\hline & $\mathrm{MIC} / 4$ & - & - \\
\hline \multirow[t]{3}{*}{ AP7 } & MIC & - & 12 \\
\hline & $\mathrm{MIC} / 2$ & - & 10 \\
\hline & $\mathrm{MIC} / 4$ & - & 8 \\
\hline $\mathrm{C}_{10} \mathrm{HSL}$ & & - & 31 \\
\hline Ethanol & & - & - \\
\hline
\end{tabular}


our DPPH results in their study. Chen, Weng, $\mathrm{Wu}$, and Lin (2004), Russo et al. (2004), Choi et al. (2006), Alencar et al. (2007), Moreira, Dias, Pereira, and Estevinho (2008), Miquel, Nunes, Dandlen, Cavaco, and Antunes (2010), Piccinelli et al. (2013) and Silva Frozza et al. (2013) reported lower $I C_{50}$ values compared to our results. Sheng, Zhou, Wang, Xu, and Hu (2007) reported results consistent with our study in the antioxidant activity experiments they conducted with the FTC method.

\section{Quorum Quenching Activities}

In the study, MIC values of biomonitor strains against propolis extracts were determined prior to the determination of antiquorum sensing activity. The highest antimicrobial effect was found in AP4, AP6 and AP7 extracts against C. violaceum CV12472 strain. The highest antimicrobial effect was seen in AP7 extract against C. violaceum CV026 strain. All of the propolis extracts used in the study showed inhibition of violacein production at different concentrations. Also, the highest inhibition of violacein production was determined in $100 \%$ at concentrations of $\mathrm{MIC}, \mathrm{MIC} / 2$ and $\mathrm{MIC} / 4$, and $51.0 \%$ at a concentration of MIC/8 for AP7 extract.

It was determined that AP4, AP6 and AP7 extracts among the propolis extracts used in the study have antiquorum sensing activity. However, there were no activity detected for AP1, AP2, AP3, AP5 for antiquorum quenching activity. The results reported by Savka et al. (2015) confirm our anti-quorum sensing results.

\section{Conclusion}

The antimicrobial effect of propolis samples collected from Milas and Bodrum (Gümüşlük) was revealed in this study. It was found that the propolis sample collected from the Milas region highly inhibited the S.mutans and S.typhimurium biofilm formation, especially at MIC concentrations. DPPH and $\beta$-carotene linoleic acid method results also revealed that Milas and Bodrum (Gümüşlük) propolis samples have high antioxidant activity as well as antimicrobial activity. Considering the antiquorum sensing results, it was determined that the Bodrum (Gümüşlük) propolis sample was effective in terms of quorum sensing inhibition.

Amongst the propolis ethanol extracts used in the study, Milas and Bodrum (Gümüşlük) samples showed the feature of being alternative in the treatment of many infections due to their antimicrobial and antibiofilm activities, and to eliminate the harmful effects of free radicals that cause many health problems, according to the antioxidant activity results. In addition, these two propolis extracts were found to be able to prevent the quorum sensing communication system used by most pathogenic bacteria to cause disease and especially to control biofilm production. Accordingly, it has been revealed that these two extracts have a potential in alternative treatment studies to be applied in the field of medicine.

\section{Acknowledgements}

This study is a part of MSc thesis and supported by Muğla Sıtkı Koçman University, with BAP 13/178 project number. In addition, this study was presented as a poster at the 45th Apimondia International Apicultural Congress and $5^{\text {th }}$ International Mugla Beekeeping and Pine Honey Congress.

\section{References}

Alencar, S. M., Oldoni, T. C., Castro, M. L., Cabral, I. S. R., CostaNeto, C. M., Cury, J. A., ... \& Ikegaki, M. (2007). Chemical composition and biological activity of a new type of Brazilian propolis: red propolis. Journal of Ethnopharmacology, 113(2), 278-283.

Anjum, S. I., Ullah, A., Khan, K. A., Attaullah, M., Khan, H., Ali, H., ... \& Adgaba, N. (2019). Composition and functional properties of propolis (bee glue): A review. Saudi Journal of Biological Sciences, 26(7), 1695-1703.

Bankova, V. S., de Castro, S. L., \& Marcucci, M. C. (2000). Propolis: recent advances in chemistry and plant origin. Apidologie, 31(1), 3-15.

Blicharska, N., \& Seidel, V. (2019). Chemical diversity and biological activity of african propolis. In: Progress in the Chemistry of Organic Natural Products 109,(pp 415-450). Springer, Cham.,

Blonska, M., Bronikowska, J., Pietsz, G., Czuba, Z. P., Scheller, S., \& Krol, W. (2004). Effects of ethanol extract of propolis (EEP) and its flavones on inducible gene expression in J774A. 1 macrophages. Journal of Ethnopharmacology, 91(1), 25-30.

Burits, M., \& Bucar, F. (2000). Antioxidant activity of Nigella sativa essential oil. Phytotherapy research, 14(5), 323328.

Capoci, I.R.G., Bonfim-Mendonça, P.D.S., Arita, G.S., Pereira, R.R.D.A., Consolaro, M.E.L., Bruschi, M.L., ... \& Svidzinski, T.I.E. (2015). Propolis is an efficient fungicide and inhibitor of biofilm production by vaginal Candida albicans. Evidence-Based Complementary and Alternative Medicine, 2015.

Chen, C.N., Weng, M.S., Wu, C.L. ve Lin, J.K. (2004). Comparison of Radical Scavenging Activity, Cytotoxic Effects and Apoptosis Induction in Human Melanoma Cells by Taiwanese Propolis from Different Sources. Evidence Based Complementary and Alternative Medicine, 1(2):175-185.

Cheng, P. C., \& Wong, G. (1996). Honey bee propolis: prospects in medicine. Bee world, 77(1), 8-15.

Choi, Y. M., Noh, D. O., Cho, S. Y., Suh, H. J., Kim, K. M., \& Kim, J. M. (2006). Antioxidant and antimicrobial activities of propolis from several regions of Korea. LWT-Food Science and Technology, 39(7), 756-761.

Choo, J. H., Rukayadi, Y., \& Hwang, J. K. (2006). Inhibition of bacterial quorum sensing by vanilla extract. Letters in Applied Microbiology, 42(6), 637-641.

Dapkevicius, A., Venskutonis, R., van Beek, T.A., \& Linssen, J.P. (1998). Antioxidant activity of extracts obtained by different isolation procedures from some aromatic herbs grown in Lithuania. Journal of the Science of Food and 
Agriculture, 77(1), 140-146.

Dogan, N., Doğanlı, G.,Ulger, G.,Habesoglu, D., Guzel, S., Yasar, Y., Arar, D.,Sensoy, T. and Bozbeyoglu, N. (2014). Antibiofilm effect of two propolis samples from Turkey. Journal of Applied Biological Sciences, 8(2), 27-31.

Ghisalberti, E.L. (1979). Propolis: a review. Bee world, 60(2), 59-84.

Gonçalves, G. M. S., Santos, N. P., \& Srebernich, S. M. (2011). Antioxidant and antimicrobial activities of propolis and açai (Euterpe oleracea Mart) extracts. Journal of Basic and Applied Pharmaceutical Sciences, 32(3).

Koh, K.H., \& Tham, F.Y. (2011). Screening of traditional Chinese medicinal plants for quorum-sensing inhibitors activity. Journal of Microbiology, Immunology and Infection, 44(2), 144-148.

Kouidhi, B., Zmantar, T., \& Bakhrouf, A. (2010). Anti-cariogenic and anti-biofilms activity of Tunisian propolis extract and its potential protective effect against cancer cells proliferation. Anaerobe, 16(6), 566-571.

Lu, L. C., Chen, Y. W., \& Chou, C. C. (2003). Antibacterial and DPPH free radical-scavenging activities of the ethanol extract of propolis collected in Taiwan. Journal of Food and Drug Analysis, 11(4), 277-282.

Marcucci, M.C. (1995). Propolis: chemical composition, biological properties and therapeutic activity. Apidologie 26(2), 83-99. DOI: 10.1051/apido:19950202.

Merritt, J. H., \& Kadouri, D. E. O, Toole, GA (2005). Growing and analyzing static biofilms. Current Protocols in Microbiology, 1.

Miguel, M. G., Nunes, S., Dandlen, S. A., Cavaco, A. M., \& Antunes, M. D. (2010). Phenols and antioxidant activity of hydro-alcoholic extracts of propolis from Algarve, South of Portugal. Food and Chemical Toxicology, 48(12), 3418-3423.

Mitsuda, H., Yuasumoto, K., Iwami, K. (1996) Antioxidation action of indole compounds during the autoxidation of linoleic acid. Journal of Japanese Society of Nutrition and Food Science, 19, 210.

Moreira, L., Dias, L.G., Pereira, J.A., \& Estevinho, L. (2008). Antioxidant properties, total phenols and pollen analysis of propolis samples from Portugal. Food and Chemical Toxicology, 46(11), 3482-3485.

Moreno, M. I.N., Isla, M.I., Sampietro, A.R., \& Vattuone, M.A. (2000). Comparison of the free radical-scavenging activity of propolis from several regions of Argentina.
Journal of ethnopharmacology, 71(1-2), 109-114.

Russo, A., Cardile, V., Sanchez, F., Troncoso, N., Vanella, A., \& Garbarino, J.A. (2004). Chilean propolis: antioxidant activity and antiproliferative action in human tumor cell lines. Life Sciences, 76(5), 545-558.

Piccinelli, A. L., Mencherini, T., Celano, R., Mouhoubi, Z., Tamendjari, A., Aquino, R. P., \& Rastrelli, L. (2013). Chemical composition and antioxidant activity of Algerian propolis. Journal of Agricultural and Food Chemistry, 61(21), 5080-5088.

Rojczyk, E., Klama-Baryła, A., Łabuś, W., WilemskaKucharzewska, K., \& Kucharzewski, M. (2020). Historical and modern research on propolis and its application in wound healing and other fields of medicine and contributions by Polish studies. Journal of Ethnopharmacology, 113159.

Savka, M.A., Dailey, L., Popova, M., Mihaylova, R., Merritt, B., Masek, M., ... \& Bankova, V. (2015). Chemical composition and disruption of quorum sensing signaling in geographically diverse United States propolis. Evidence-Based Complementary and Alternative Medicine, 2015.

Scazzocchio, F., D’auria, F. D., Alessandrini, D., \& Pantanella, F. (2006). Multifactorial aspects of antimicrobial activity of propolis. Microbiological Research, 161(4), 327-333.

Sheng, J., Zhou, J., Wang, L., Xu, J., \& Hu, Q. (2007). Antioxidant activity of ethanol and petroleum ether extracts from Brazilian propolis. European Food Research and Technology, 225(2), 249.

Silva Frozza, C.O., Garcia, C.S.C., Gambato, G., de Souza, M. D.O., Salvador, M., Moura, S., ... \& Dellagostin, O.A. (2013). Chemical characterization, antioxidant and cytotoxic activities of Brazilian red propolis. Food and Chemical Toxicology, 52, 137-142.

Talla, E., Tamfu, A.N., Gade, I. S., Yanda, L., Mbafor, J.T., Laurent, S., ... \& Bankova, V. (2017). New mono-ether of glycerol and triterpenes with DPPH radical scavenging activity from Cameroonian propolis. Natural Product Research, 31(12), 1379-1389.

Tamfu, A.N., Sawalda, M., Fotsing, M.T., Kouipou, R.M.T., Talla, E., Chi, G.F., ... \& Shaheen, F. (2020). A new isoflavonol and other constituents from Cameroonian propolis and evaluation of their anti-inflammatory, antifungal and antioxidant potential. Saudi Journal of Biological Sciences, 27(6), 1659-1666. 